\title{
openheart Trends in the incidence and prevalence of cardiac pacemaker insertions in an ageing population
}

\author{
Pamela J Bradshaw, ${ }^{1}$ Paul Stobie, ${ }^{2}$ Matthew W Knuiman, ${ }^{1}$ Thomas G Briffa, ${ }^{1}$ \\ Michael S T Hobbs ${ }^{1}$
}

To cite: Bradshaw PJ, Stobie P, Knuiman MW, et al. Trends in the incidence and prevalence of cardiac pacemaker insertions in an ageing population. Open Heart 2014;1:e000177. doi:10.1136/openhrt-2014000177

Received 31 July 2014 Revised 11 November 2014 Accepted 18 November 2014

\section{(a) CrossMark}

${ }^{1}$ School of Population Health, The University of Western Australia, Perth, Western Australia, Australia ${ }^{2}$ Department of Cardiovascular Medicine, Sir Charles Gairdner Hospital, Perth, Western Australia, Australia

\section{Correspondence to} Dr Pamela J Bradshaw; pamela.bradshaw@.uwa.edu. au

\section{ABSTRACT}

Objectives: To determine contemporary population estimates of the prevalence of cardiac permanent pacemaker (PPM) insertions.

Methods: A population-based observational study using linked hospital morbidity and death registry data from Western Australia (WA) to identify all incident cases of PPM insertion for adults aged 18 years or older. Prevalence rates were calculated by age and sex for the years 1995-2009 for the WA population.

Results: There were 9782 PPMs inserted during 1995-2009. Prevalence rose across the study period, exceeding 1 in 50 among people aged 75 or older from 2005. This was underpinned by incidence rates which rose with age, being highest in those 85 years or older; over 500/100 000 for men throughout, and over 200/ 100000 for women. Rates for patients over 75 were more than double the rates for those aged 65-74 years. Women were around $40 \%$ of cases overall. The use of dual-chamber and triple-chamber pacing increased across the study period. A cardiac resynchronisation defibrillator was implanted for $58 \%$ of patients treated with cardiac resynchronisation therapy.

Conclusions: Rates of insertion and prevalence of PPM continue to rise with the ageing population in WA. As equilibrium has probably not been reached, the demand for pacing services in similarly well-developed economies is likely to continue to grow.

\section{INTRODUCTION}

Rates of permanent pacemaker (PPM) insertion increase with age, with an estimated $70-80 \%$ of all PPMs being implanted in patients 65 years of age or older. ${ }^{1}$ With the ageing of populations worldwide associated with increased life expectancy and the ageing of the post-World War II 'baby boom' cohort, currently most evident in developed countries, ${ }^{2}$ estimates of population rates of PPM have continued to rise in most countries. ${ }^{3-8}$

Rising incidence and declining mortality contribute to increasing prevalence, with the associated burden of replacement of devices in addition to initial insertions. There is very little information on PPM prevalence for any

\section{KEY QUESTIONS}

What is already known about this subject?

- Rates of cardiac pacemaker implantation rise with age and populations worldwide are ageing.

What does this study add?

- The rising trends in age-specific rates of PPM use are demonstrated, as is a greater than anticipated doubling of prevalence rates in 15 years in a developed economy.

How might this impact on clinical practice?

- This study suggests that the demand for pacing services will continue to grow as populations age.

country. One of the few reports comes from the Medical Device Implant Supplement to the 1988 US National Health Interview Survey. ${ }^{9}$ Population overall prevalence was estimated at 260/100 000; 40/100 000 for people aged 18-64 and 2600/100 000 for those aged $\geq 75$ years. A Danish regional population had lower estimates, being 172/100 000 for men and 147/100000 for women overall in 1990 . The rates for older patients ranged from 1102/100 000 for men aged 75-79 to 2454/ 100000 for those aged $\geq 90$ years. ${ }^{10}$ The authors predicted that the prevalence rate could double within 25 years if annual insertions continued to exceed deaths. This rapid increase was evident among Medicare (US) recipients of PPMs (age $\geq 65$ years), with age-standardised prevalence estimated at 325.4, 399.7 and 504.4 per 100000 enrolees in 1990, 1995 and 2000, respectively. ${ }^{11}$

Having documented a rapid rise in the population rates of insertions of automated implantable cardioverter defibrillator (AICD), especially in those aged 65 years or older, ${ }^{12}$ we aimed to determine contemporary estimates of trends in the age-specific incidence and prevalence of PPM use for the years 19952009, using linked data from an Australian state population. Australia is a developed 
economy with universal healthcare, comparable with countries such as Canada, the UK and parts of Europe.

\section{METHODS}

This retrospective cohort study uses linked data prepared by the Data Linkage Branch of the Health Department of Western Australia. The data linkage system has been described in detail elsewhere. ${ }^{13}$

\section{Ascertainment of cases}

Data for the study were extracted from a linked file of all admissions, discharges and deaths among the population of Western Australia (WA), who were hospitalised for, or died from, cardiovascular disease and associated conditions since 1980 (WHO International Classification of Disease (ICD) V.9, 9-CM diagnostic codes 390-459, and 10-Australian Modification codes I00-I99) including all cardiac procedures. All records with a procedure or diagnosis code for insertion or management of a cardiac pacing device, and all admissions for each individual with such a record, formed the study database. The following information was collected: hospital admission and separation dates, and date of death to 31 December 2009, principal diagnosis and up to 19 secondary diagnoses, and up to 11 in-hospital procedures identified using WHO-ICD codes (available from the first author).

While WHO-ICD-9 codes distinguished 'initial' and 'replacement' insertion of a PPM, ICD-10-Australian Modification (ICD-10-AM) codes, introduced in mid-1999, did not. To identify initial insertions, a standard look-back of 15 years was used to find the first hospitalisation for a PPM-related procedure from 1995; this was considered the initial event, as pacemaker battery life infrequently exceeds 15 years. Pacemaker type (single, dual, triple chamber or 'not otherwise specified') was identified from the procedure codes for the insertion of the device. Where this was not specified, codes for lead placement (if specified) were used to determine the number of chambers paced. Biventricular pacing (cardiac resynchronisation therapy, CRT) was assigned specific WHO-ICD-10-AM codes from 2004 to mid-2008. This allowed identification of CRT pacemakers as well as CRT defibrillators (CRT-D), but from July 2008 'insertion of a pacemaker generator' and insertion of a 'permanent electrode into other heart chambers' for a pacemaker were each reduced to a single code. This does not allow the identification of single, dual or triple chamber pacing. Similarly, the single code for the insertion of an ICD includes those devices that combine the defibrillator with CRT capacity. Patients who had codes for both pacing and AICD were included but not those with an AICD code alone. The major indications for PPM insertion were categorised using diagnosis and procedure codes based on those used in the world surveys, ${ }^{5}$ and in a hierarchical fashion (major indication in principal diagnosis, secondary diagnosis, etc).

Validation of the coding of insertion of PPMs in the hospital morbidity data (HMD) was undertaken first by comparing cases drawn from a teaching hospital coronary catheter laboratory database with the HMD. Cases not found in either data sets were checked against the patient's medical records. In addition, annual counts of new and replacement PPMs in WA based on hospital admission data were compared with sales figures published in quadrennial surveys conducted between 1997 and 2009, ${ }^{14-17}$ and with total annual sales numbers for the State (2006-2009) compiled within the WA Department of Health.

\section{Calculation of population incidence and prevalence rates}

WA adult ( $\geq 20$ years) population incidence was calculated for each year from 1995 to 2009 with the denominators being taken from Australian census years 1991, 1996, 2001 and 2006, and the Australian Bureau of Statistics mid-year population estimates used for intermediate years, for age groups 20-54 (pooled), 55-64, 65-74, 7584 and $85+$ years. ${ }^{18} 19$ As insertion rates were high among the elderly, prevalence correction was applied to the denominators (prevalent cases in that year were subtracted from the population to give the population at risk'), reducing the risk for underestimation of agespecific incidence rates. The age-standardised rates were standardised by the direct method against the 2009 population estimates.

Prevalence of PPM use among adults was calculated from 1995 using a standard 15-year look-back. For each year from 1995 the prevalence was calculated at 30 June using the number of patients still alive with at least one PPM-related admission (including adjustments, revisions, replacements and removals) in the previous 15 years as the numerator, and the population size as the denominator.

For comparison of linked data-based population rates with those based on sales, as published in the quadrennial Australian-New Zealand surveys, ${ }^{14-17}$ we used the total WA population for the years 1997, 2001, 2005 and 2009 as the denominator, as was done in those surveys.

Primary outcomes were trends in the demographics, incidence and prevalence of PPM insertions in the adult population of WA.

\section{Statistical analysis}

The recipients of PPMs are described, with differences between groups defined by age, sex, era of insertion (5-year intervals) and reason for insertion. Differences in mean age of the groups were tested with the ' $t$ test' and the $\chi^{2}$ test was used to compare groups defined by categorical variables. A 'p' value of $<0.05$ was considered statistically significant. Analyses were performed using SPSS Statistics for Windows, V.21.0 (IBM Corp, Armonk, New York, USA).

\section{RESULTS}

Of 15346 cases recorded for the years 1980-2009 with any pacemaker-related procedure, 9782 were incident cases of PPM insertion for the years 1995-2009. The numbers of new PPMs inserted rose steadily across the 
study period, from 2240 for the period 1995-1999 to 4365 for 2005-2009.

The mean age at insertion rose from 73.8 (SD 11.7) years in 1995-1999 to 75.3 (SD 11.7) years in 2005-2009 $(\mathrm{p} \leq 0.001)$. Women were 2 years older overall $(76.2$, SD 11.5 years vs 74.2 , SD 11.5 years, $\mathrm{p}<0.001)$ and comprised $40 \%$ of the study cohort throughout. The proportion of cases aged 75 years or older rose from $54 \%$ in 1995 1999 to $62 \%$ thereafter.

\section{Incidence}

The annual incidence of insertions rose from 32/ 100000 of the adult population in 1995 to $58 / 100000$ in 2005 and 53/100000 in 2009. Rates increased throughout for men as well as women. Women were less than $40 \%$ of patients under 75 years, and even among the oldest patients, $\geq 85$ years, their proportion $(48 \%)$ did not exceed that for men. The WA age-standardised rates were similar: $37.8 / 100000$ (95\% CI 34.1 to 41.6$)$ in 1995 to 59.6/100 000 (55.6-63.6) in 2005 and 53.4/ $100000(49.9-56.9)$ in 2009.

Incidence rates increased with age, being highest in those 85 years or older (figure 1) among whom rates were $>500 / 100000$ for men and >200/100 000 for women throughout. The rate increases were most evident among patients aged $\geq 75$ years, while remaining under $6 / 100000$ in those $<55$ years. Among older patients the average annual increase in the prevalence-corrected incidence rate ranged from 1.03 in men 65-74 years to 1.04 for men over 85 years. For women the average increase was 1.025 in those aged 65-74 years to 1.05 for those over 85 years.

\section{Prevalence}

The number of adults living with a PPM rose sharply from 2268 in 1995 to 7739 in 2009, with prevalence rates rising from 186 to 469 per 100000 . The rise in prevalent cases outstripped population growth (figure 2). Prevalence increased markedly with age, being highest among those

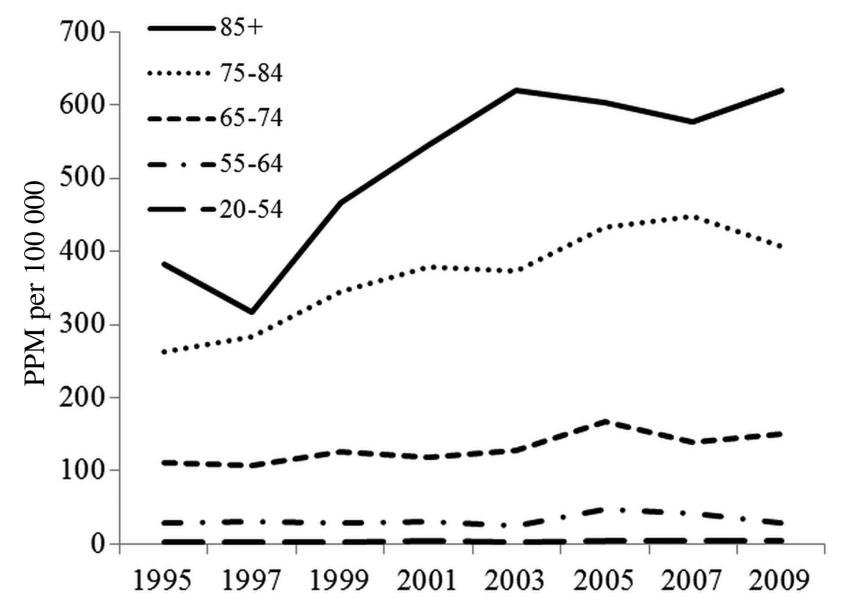

Figure 1 Trends in prevalence-adjusted incidence of permanent pacemaker insertion (per 100000 ) by age group, 1995-2009. aged 75-84 years, and has exceeded 2000/100 000 for those aged over 75 years since 2005 (figure 3). The average annual rate of growth between 1995 and 2009 was $7 \%$ overall; least for those aged $55-64$ years $(3 \%)$, highest for those $18-54$ years $(8 \%)$ although on low numbers, $6 \%$ for $65-76$ years and $7 \%$ for those $75-84$ and 85 years or older.

\section{Indications and pacemaker type}

Little change was seen in the major indications for PPMs across the study period; high-level atrioventricular block (HLB; $3^{\circ}$, Mobitz type II and other $2^{\circ}$ blocks) was the most frequent major indication across the study period, although falling from $41 \%$ of cases in 1995-1999 to 33\% for 2005-2009. Bundle branch block (BBB) and sick sinus syndrome (SSS) remained around $12 \%$ of cases each, while atrial fibrillation increased from $12 \%$ to 16\%. There were 232 postablation (surgical, radiofrequency or cryoablation) cases. There was little difference between men and women in the indications for a PPM; women were somewhat more likely to be diagnosed with SSS $(16 \%$ vs $11 \%, \mathrm{p}<0.001)$ and less likely to have either HLB or BBB block ( $45 \%$ vs $51 \%$, p $<0.001$ ).

Dual-chamber pacing was predominant from 1995, being double that of single-chamber, with increasing use of triple-chamber (biventricular) pacing seen from 2004 (when it was $<5 \%$ ).

While ICD-10 coding changes makes quantification of PPM types difficult from 2008, between 2004 and 2007 there were $252(8 \%)$ triple-chamber insertions (presumed CRT) among 3284 first PPM insertions. Of these, $146(58 \%)$ had additional codes indicating the use of a combined CRT-D device. The proportion of CRT-D as a first biventricular PPM rose from 54\% in 2004 to $64 \%$ in 2007 , and was $59 \%$ for men and $55 \%$ for women overall $(\mathrm{p}=0.35)$.

CRT was $14 \%$ of all PPM for patients aged $<55$ years, falling to $6 \%$ for $75-84$-year-olds and $1 \%$ for those aged 85 years or more. The proportion of CRT-D also decreased with age, being $82 \%, 66 \%, 65 \%, 40 \%$ for

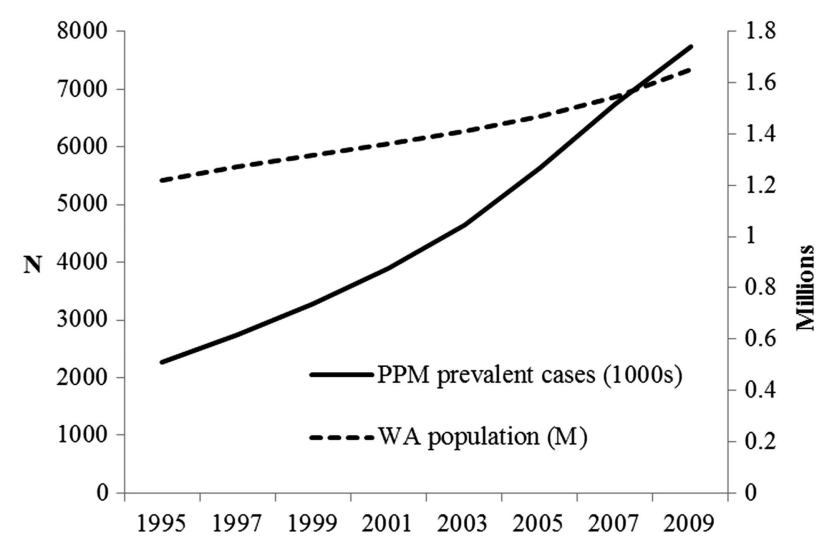

Figure 2 Growth in the adult population of WA and in the prevalence of cases with a cardiac pacemaker, 1995-2009 (PPM, permanent pacemaker; WA, Western Australia). 


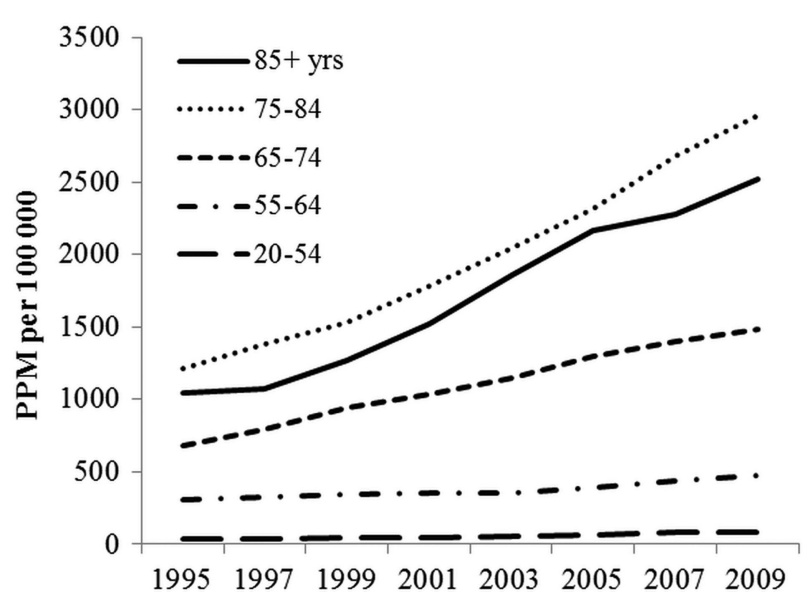

Figure 3 Trend in prevalence rates of cardiac pacemakers by age group, 1995-2009 (PPM, permanent pacemaker).

those aged $<55,55-64,65-74$ and $75-84$ years, respectively $(p<0.001)$. Only eight patients aged $\geq 85$ years $(1 \%)$ had a CRT-device implanted during 2004-2007.

\section{Validation studies}

Seven of 210 PPM procedures (3\%) from a teaching hospital catheter laboratory database for the year 1997 were not identified in the HMD, 3 of whom (1.4\%) had confirmation of a PPM procedure in their medical record. Five cases in HMD were not in the catheter laboratory database, three of whom had only a 'device check' during hospitalisation.

Rates per million of new devices implanted in WA for the years 1997, 2001 and 2005 were 233, 320 and 422, respectively, for the HMD (an underestimate, as cases $<18$ years were not included), lower than the estimates from respective sales figures of 299, 338 and 532.

Compared with quadrennial estimates from sales figures in 1997, 2001, 2005, HMD estimates of incident annual cases were $12 \%, 6 \%$ and $20 \%$ lower, respectively.

\section{DISCUSSION}

Incidence and prevalence rates of PPM insertion rose throughout the 15 years of this study, with rates highest in those over 75 years of age, and the increases most evident in this older group of patients. Incidence rates for men exceeded those for women throughout, as in other countries, including in the very elderly (age $>85$ years). ${ }^{102021}$ The rising prevalence was a function of the rising rate of PPM insertions accompanied by falling death rates in WA, the standardised death rate falling from 6.5 deaths per 1000 standard population in 1995 to 5.5 in 2010 (a decrease of $26 \%$ ). ${ }^{22}$

Ageing is associated with increases in arrhythmias and conduction disorders. ${ }^{23}$ This factor, with the increase in numbers of elderly within populations, leads to the increase in incidence evident for more than 30 years in studies from the USA ${ }^{21} 2425$ and Denmark. ${ }^{10}$ As elsewhere, the median age of Western Australians is rising, ${ }^{18}$ with no strong indication from our data that the associated rates of PPM use among the aged has plateaued, although there was an apparent flattening of growth in the prevalence-corrected rate of new insertions among those aged $75-84$ years.

While we were not able to capture the increasing use of CRT beyond 2007, the overall use of these devices increased in WA, with CRT-D being 58\% of devices, similar to the $57 \%$ reported from the European MASCOT study (2003-2006) ${ }^{26}$ In a recent study from a single centre in the UK (2000-2009), CRT-D exceeded $80 \%$ of implants for CRT. ${ }^{27}$

Incidence rate increases of PPM use are evident in most countries reporting for the quadrennial world surveys, ${ }^{3-7}$ although rates per million in a few high-use countries (Belgium, Italy, the UK and Australia) were lower in 2009 than 2005. This may be a sign that rates have plateaued in those countries, although numbers of new implants (except in Belgium) were higher. The authors of the world surveys acknowledge that the varying sources of PPM data, and the documenting of demographics, has been a challenge, ${ }^{7}$ so more data may be needed to demonstrate real change. A recent report from a Swedish registry did suggest a levelling off of growth for pacing devices in 2012 from the previous years, while AICD and CRT-D rates per million were still rising. ${ }^{28}$

Incidence rates in WA of PPM use were highest in those aged $\geq 85$ years of age, and this is consistent with other studies of age-specific incidence. ${ }^{21} 2510$ Other studies, including some from Europe, that report distribution by age for initial insertions show that approximately $80 \%$ of PPM are inserted in those 70 or more years of age, and half of those in patients 80 years or older. ${ }^{29-31}$ Those 80 years or over are the fastest growing segment of the world population aged 60 years or over, ${ }^{2}$ suggesting that incident rates may not yet have plateaued in this Australian population, or others where the median age is rising.

The PPM insertion rate of 534 per million in 2009 in our study is similar to estimates from many European countries. ${ }^{7}$ Comparisons are hampered by the lack of age adjustment, however, the highest rates reported (>700 per million) are from Germany, Italy, France and Sweden, where the median age is greater than Australia, and the USA where the median age is similar (figure 4). ${ }^{32}$ The correlation between median age and use of PPMs is only fair, with countries such as the USA and Germany having rates above those expected. Population projections can provide a guide to future incidence, although factors such as the structure of the healthcare system, and physician and patient beliefs and expectations about the appropriate levels of care may also influence the rates of PPM insertion. Where there is disparity within countries by region or population sector, such as reported from the highly developed economy of Sweden, ${ }^{28}$ there is potential for continuing growth in demand, even if population factors are stable.

Prevalence rates more than doubled within the 15-year study period, exceeding the prediction of a doubling of 


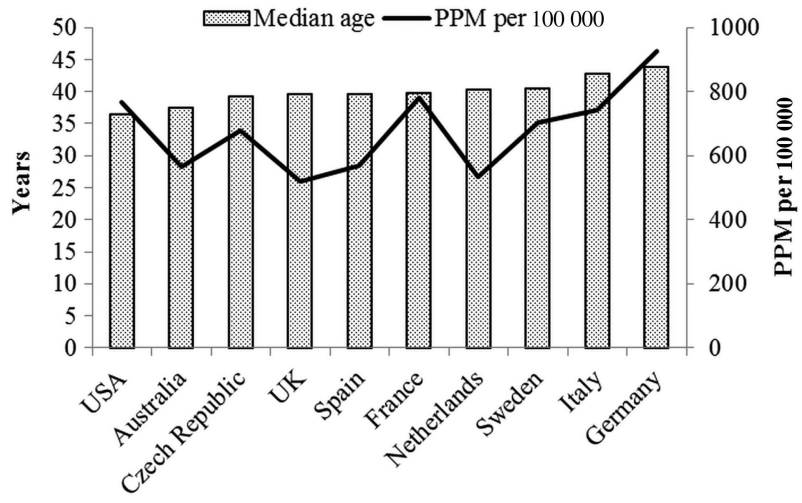

Figure 4 Median age ${ }^{32}$ and new cardiac pacemaker implants per million ${ }^{7}$ for 10 developed countries in 2009 (PPM, permanent pacemaker).

the prevalence rate in 25 years from 1990 made from Danish regional population data. ${ }^{10}$ Prevalent cases tripled, so that since 2005 at least 1 in 50 of those aged 75 or older in WA have had a PPM inserted.

As there is no strong evidence that the age-related trend to increasing PPM use has plateaued, the implications from these findings are that health services worldwide can anticipate an increasing need for cardiac electrophysiological/pacing services, with the demand for initial implants rising with the ageing population. This is for pacing alone; the growth in the use of AICDs and CRT-D devices must also be taken into account. ${ }^{3-7} 3312$ Even though the use of CRT was greater in the younger patients, the increasing prevalence of these devices, and improvements in life expectancy for recipients, ${ }^{34}$ will add to the demand for ongoing management, revision and replacement of PPMs. These demands are unlikely to ease in the short term, as the replacement rate has remained steady despite improvements in devices and battery life. ${ }^{35}$

\section{Strengths and weaknesses}

This study benefits from access to more than 30 years of high-quality, population-level, person-based linked data, allowing researchers to look back over decades to identify incident and prevalent cases of PPM insertion. The validity of the matching for the HMD has been assessed, with invalid links (false positives) and missed links (false negatives) estimated at $0.11 \%$ each. ${ }^{13}$ WA is a state of net immigration; deaths outside the state have been estimated at less than $5 \% .^{36}$

Validation of coding of procedures in the HMD matched those from a catheter laboratory database and medical records with no more than $2 \%$ of false positives and false negatives, and the coding of cardiac diagnoses has been found to have high validity over time, most recently in a study of heart failure. ${ }^{37}$

These findings from WA can be broadly generalised to the wider Australian population as, despite insertion rates calculated from sales being lower than in the more populous states, ${ }^{14-17}$ WA has a lower median age. ${ }^{18}$ The trends can provide estimates to guide health service planning in similarly developed countries.

\section{Validity of population estimates based on administrative data}

There is no accepted 'gold standard' for estimates of PPM use. Several countries in the European Union maintain PPM registries using an identification card system to collect individual data on insertions of cardiac devices. Voluntary notification means that these data may be incomplete and must be supplemented or replaced by hospital-based surveys or sales figures provided by medical technology companies. ${ }^{7} 31$

In this study aggregated, person-level hospital administrative data were a valid tool for estimating incidence and prevalence, although estimates from the WA administrative data were lower by $6-20 \%$ than sales-based surveys. ${ }^{14-17}$ The exclusion of children, and the inclusion of only incident, first-ever implantations is likely to account for the difference. Probable overestimation of device use using sales data compared with administrative data has been reported from the USA, where reported sales exceeded by more than $10 \%$ the hospital admissions-based National Inpatient Sample data, ${ }^{25}$ and in France by $7 \% .^{20}$

\section{Weaknesses}

Indications for pacing derived from patients' medical records would more accurately reflect clinical decisions than administrative data, where multiple competing indications may be coded. The use of a hierarchical method to categorise the WHO-ICD clinical codes, that is, the most likely major indication such as SSS or HLB are given precedence over conditions such as acute myocardial infarction, heart failure or syncope, does allow the determination of trends in major indications.

Changes to the coding of procedures (health interventions) in recent editions of the Australian Modification of the WHO-ICD-10 have significantly reduced the level of detail, affecting the measurement of current trends in pacemaker use. Since 2008, it is difficult to identify the number of chambers paced by analysis of the coding. Individual chart review was beyond the scope of this study. The apparent fall in PPM insertions (2009 data) may relate to the increased use of combined defibrillator/CRT devices for management of heart failure, and our inability to identify those devices that combine AICD and pacing functions, or it may signal a levellingoff of demand after a period of continued growth.

\section{CONCLUSIONS}

The demand for cardiac pacing is strongly related to ageing, driving the trends to rising rates of incidence and prevalence. With continued ageing of the population the demand for electrophysiology/pacing services is likely to continue to increase. 
Acknowledgements The authors thank the data custodians, data linkage and client services staff of Department of Health WA for assistance with gaining approvals and the linkage, extraction and checking of the linked data.

Contributors PJB planned the study, undertook the data analysis and interpretation, and drafted the article. In addition to providing input into study design and critical revision, and approval of the article, MSTH obtained the funding, PS provided clinical advice and MWK advised on statistics. The authors had full access to all of the data (including statistical reports and tables) in the study.

Funding This work was supported by a project grant from The Heart Foundation of Australia (Grant No. G 08A 3656) obtained initially by the late Professor Konrad Jamrozik.

Competing interests PS has participated in Advisory Board meetings for Medtronic, Inc and St Jude Medical, Inc.

Ethics approval The study was approved by the Human Research Ethics Committees at the University of Western Australia and Health Department of Western Australia.

\section{Provenance and peer review Not commissioned; externally peer reviewed.}

Data sharing statement Only summary data from this linked data set are available to other researchers. Access to the Western Australia linked data is available only through the Health Department of Western Australia to approved researchers and after HREC approval has been obtained.

Open Access This is an Open Access article distributed in accordance with the Creative Commons Attribution Non Commercial (CC BY-NC 4.0) license, which permits others to distribute, remix, adapt, build upon this work noncommercially, and license their derivative works on different terms, provided the original work is properly cited and the use is non-commercial. See: http:// creativecommons.org/licenses/by-nc/4.0/

\section{REFERENCES}

1. Gregoratos G. Permanent pacemakers in older persons. J Am Geriatr Soc 1999;47:1125-35.

2. United Nations, Department of Economic and Social Affairs, Population Division. World Population Ageing: 1950-2050. New York, 2001. http://www.un.org/esa/population/publications/ worldageing19502050/

3. Mond HG. The World Survey of Cardiac Pacing and Implantable Cardioverter-Defibrillators: calendar year 1997. Asian Pacific, Middle East, South America, and Canada. Pacing Clin Electrophysiol 2001;24:856-62.

4. Ector H. Rickards AF, Kappenberger L, et al. The World Survey of Cardiac Pacing and Implantable Cardioverter-Defibrillators: calendar year 1997-Europe. Pacing Clin Electrophysiol 2001;27:863-8.

5. Mond HG, Irwin M, Morillo C, et al. The World Survey of Cardiac Pacing and Cardioverter-Defibrillators: calendar year 2001. Pacing Clin Electrophysiol 2004;27:955-64.

6. Mond HG, Irwin M, Ector H, et al. The World Survey of Cardiac Pacing and Cardioverter-Defibrillators: calendar year 2005. PACE 2008;31:1202-12

7. Mond HG, Proclemer A. The 11th World Survey of Cardiac Pacing and Cardioverter-Defibrillators: calendar year 2009. Pacing Clin Electrophysiol 2011;34:1013-27.

8. Ector $\mathrm{H}$, Vardas $\mathrm{P}$. Current use of pacemakers, implantable cardioverter defibrillators, and resynchronization devices: data from the registry of the European Heart Rhythm Association. Eur Heart $J$ Supp/ 2007:9(Suppl 1):144-9.

9. Silverman BG, Gross TP, Kaczmarek RG, et al. The epidemiology of pacemaker insertion in the United States. Public Health Rep 1995;110:42-6

10. Andersen C, Green A, Madsen GM, et al. The epidemiology of pacemaker insertions in Fyn county, Denmark. Pacing Clin Electrophysiol 1991;14:1614-21.

11. Brown D, Croft J, Giles W, et al. Epidemiology of pacemaker procedures among Medicare enrollees in 1990, 1995, and 2000. Am J Cardiol 2005;95:409-11.

12. Bradshaw PJ, Stobie P, Briffa T, et al. Use and long-term outcomes of implantable cardioverter-defibrillators, 1990 to 2009. Am Heart J 2013;65:816-22.

13. Holman C, Bass A, Rouse I, et al. Population-based linkage of health records in Western Australia: development of a health services research linked database. Aust NZ J Public Health 1999;23:453-9.

14. Mond HG, Whitlock RML. The Australian and New Zealand Cardiac Pacing and Implantable Cardioverter-Defibrillator Survey: calendar year 1997. Intern Med J 2001;31:267-71.

15. Mond HG, Whitlock RML. The Australian and New Zealand Cardiac Pacing and Implantable Cardioverter-Defibrillator Survey: calendar year 2001. Heart Lung Circ 2004;13:145-9.

16. Mond HG, Whitlock RML. The Australian and New Zealand Cardiac Pacing and Implantable Cardioverter-Defibrillator Survey: calendar year 2005. Heart Lung Circ 2008;17:85-9.

17. Mond HG, Whitlock RML. The Australian and New Zealand Cardiac Pacing and Implantable Cardioverter-Defibrillator Survey: calendar year 2009. Heart Lung Circ 2011;20:99-104.

18. Australian Bureau of Statistics 3235.0-2009. Population by Age and Sex, Regions of Australia. http://www.abs.gov.au/ausstats/abs@.nsf/ Products/3235.0 2009 Main+Features Western+Australia

19. Australian Bureau of Statistics 3101.0-Australian Demographic Statistics, June 1990 PDF http://www.abs.gov.au/AUSSTATS/abs@ nsf/DetailsPage/3101.0Jun\%201990

20. Tuppin P, Neumann A, Marijon E, et al. Insertion and patient profiles for pacemakers and cardioverter-defibrillators in France (20082009). Arch Cardiovasc Dis 2011;104:332-42.

21. Uslan D, Tleyjeh I, Baddour L, et al. Temporal trends in permanent pacemaker insertion: a population-based study. Am Heart $J$ 2008;155:896-903.

22. Australian Bureau of Statistics. Deaths, Australia, 2010. Cat. No. 3302.0 http://www.abs.gov.au/ausstats/abs@.nsf/Products/3302. 0 2010 Chapter Main+Features?OpenDocument

23. Chow GV, Marine JE, Fleg JL. Epidemiology of arrhythmias and conduction disorders in older adults. Clin Geriatr Med 2012;28:539-53.

24. Zhan C, Baine WB, Sedrakyan A, et al. Cardiac device insertion in the United states from 1997 through 2004: a population-based analysis. J Gen Intern Med 2008;23(Suppl 1):13-19.

25. Birnie D, Williams K, Guo A, et al. Reasons for escalating pacemaker implants. Am J Cardiol 2006;98:93-7.

26. Schuchert A, Muto C, Maounis T, et al. for the MASCOT study group. Lead complications, device infections, and clinical outcomes in the first year after implantation of cardiac resynchronization therapy-defibrillator and cardiac resynchronization therapy-pacemaker. Europace 2013;15:71-6.

27. Ahsan S, Saberwal B, Lamblase P, et al. An 8-year single-centre experience of cardiac resynchronisation therapy: procedural success, early and late complications, and left ventricular lead performance. Europace 2013;15:711-17.

28. Gadler F, Valzania C, Linde C. Current use of implantable electrical devices in Sweden: data from the Swedish pacemaker and implantable cardioverter-defibrillator registry. Europace Published Online First: 21 Oct 2014

29. Urra FG, Lezcano AO. MAMI registration report 1996-2010. Cardiol J 2012;19:603-11.

30. Proclemer A, Ghidina M, Gregori D, et al. Trend of the main clinical characteristics and pacing modality in patients treated by pacemaker: data from the Italian Pacemaker Registry for the quinquennium 2003-07. Europace 2010;12:202-9.

31. Coma Samartín R, Martínez Ferrer J, Sancho Tello MJ, et al. Spanish pacemaker registry. Fifth official report of the Spanish Society of Cardiology Working Group on Cardiac Pacing (2007). Rev Esp Cardiol (Engl Ed) 2008;61:1315-28.

32. World Population Ageing. Population Division, Department of Economic and Social Affairs. United Nations, New York 2009. http:// www.un.org/esa/population/publications/WPA2009/WPA2009 WorkingPaper.pdf

33. Merkely B, Roka A, Kutyifa V, et al. Tracing the European course of cardiac resynchronization therapy from 2006 to 2008. Europace 2010;12:692-701.

34. Khazanie P, Hammill BG, Qualls LG, et al. Clinical effectiveness of cardiac resynchronization therapy vs medical therapy alone among patients with heart failure: an analysis of the ICD and ADHERE national registries. Circ Heart Fail 2014;7:926-34.

35. Kurtz SM, Ochoa JA, Lau E, et al. Implantation trends and patients profiles for pacemakers and implantable cardioverter defibrillators in the United Sates: 1993-2006. Pacing Clin Electrophysiol 2010;33:705-11.

36. Bradshaw PJ, Jamrozik K, Jelfs $P$, et al. Mobile Australians: a moving target for epidemiologists. Med J Aust 2000;172:566.

37. Teng TH, Finn J, Hung J, et al. A validation study: how effective is the Hospital Morbidity Data as a surveillance tool for heart failure in Western Australia? Aust N Z J Public Health 2008;32:405-7. 